\title{
Pipeline-assisted coil embolization of a large middle cerebral artery pseudoaneurysm in a 9-month-old infant: experience from the youngest flow diversion case
}

\author{
Geoffrey P. Colby, MD, PhD, ${ }^{1,2}$ Bowen Jiang, MD, ${ }^{1}$ Matthew T. Bender, MD, ${ }^{1}$ Narlin B. Beaty, MD, ${ }^{1}$ \\ Erick M. Westbroek, MD, ${ }^{1}$ Risheng Xu, MD, PhD, ${ }^{1}$ Li-Mei Lin, MD, ${ }^{1,3}$ Jessica K. Campos, MD, ${ }^{1}$ \\ Rafael J. Tamargo, MD, ${ }^{1}$ Judy Huang, MD, ${ }^{1}$ Alan R. Cohen, MD, ${ }^{1}$ and Alexander L. Coon, MD1 \\ 1Department of Neurosurgery, Johns Hopkins School of Medicine, Baltimore, Maryland; '2Department of Neurosurgery, UCLA \\ Medical Center, Los Angeles, California; and ${ }^{3}$ Department of Neurosurgery, UC Irvine Medical Center, Orange, California
}

\begin{abstract}
Intracranial aneurysms in the pediatric population are rare entities. The authors recently treated a 9-month-old infant with a 19-mm recurrent, previously ruptured, and coil-embolized left middle cerebral artery (MCA) pseudoaneurysm, which was treated definitively with single-stage Pipeline-assisted coil embolization. The patient was 5 months old when she underwent resection of a left temporal Grade 1 desmoplastic infantile ganglioglioma at an outside institution, which was complicated by left MCA injury with a resultant $9-\mathrm{mm}$ left $\mathrm{M}_{1}$ pseudoaneurysm. Within a month, the patient had two aneurysmal rupture events and underwent emergency craniectomy for decompression and evacuation of subdural hematoma. The pseudoaneurysm initially underwent coil embolization; however, follow-up MR angiography (MRA) revealed aneurysm recanalization with saccular enlargement to $19 \mathrm{~mm}$. The patient underwent successful flow diversion-assisted coil embolization at 9 months of age. At 7 months after the procedure, follow-up MRA showed complete aneurysm occlusion without evidence of in-stent thrombosis or stenosis. Experience with flow diverters in the pediatric population is still in its early phases, with the youngest reported patient being 22 months old. In this paper the authors report the first case of such a technique in an infant, whom they believe to be the youngest patient to undergo cerebral flow diversion treatment.
\end{abstract}

https://thejns.org/doi/abs/10.3171/2018.6.PEDS18165

KEYWORDS Pipeline embolization device; coil embolization; aneurysm; infant; flow diversion; vascular disorders

$\mathrm{P}$ EDIATRIC intracranial aneurysms are rare clinical entities with unique management challenges and considerations. Historically, microsurgical clipping was favored for its benefit of long-term aneurysmal obliteration over the extended lifespan in the pediatric population..$^{39}$ Over the last decade, the treatment paradigm for aneurysms has experienced a shift from open surgery to endovascular therapy in the adult population, ${ }^{10,26}$ and this trend has extended into the pediatric population..$^{33,44}$ The Pipeline embolization device (PED; Medtronic Neurovascular) and other flow diversion technologies are increasingly important tools of modern neurointervention in the management of cerebral aneurysms. ${ }^{5-7,18,28,38}$ The PED has been adopted successfully for small aneurysms of both the anterior and posterior circulations as well as in the distal circulations beyond the circle of Willis., ${ }^{4,11,16,17}$ However, the use of flow diverters in the pediatric population $(<18$ years of age) has been limited, with only 21 reported patients in the literature (Table 1), none of whom were infants $(<1 \text { year old). })^{3,7,12,14,19,20,29,32,35,41,46,48,49}$

We present a case of PED-assisted coil embolization for definitive management of a large, previously ruptured, and coiled recurrent left middle cerebral artery (MCA) pseudoaneurysm in a 9-month-old girl. To our knowledge, this represents the first case of flow diversion embolization in an infant.

\section{Case Report}

History and Imaging

A previously healthy, full-term, 5-month-old girl presented with seizures and apnea and was found to have a

ABBREVIATIONS EVD = external ventricular drain; ICA = internal carotid artery; $M C A=$ middle cerebral artery; $M R A=M R$ angiography; $P E D=$ Pipeline embolization device; PRU = platelet response units; STA = superficial temporal artery.

SUBMITTED March 19, 2018. ACCEPTED June 4, 2018.

INCLUDE WHEN CITING Published online August 24, 2018; DOI: 10.3171/2018.6.PEDS18165. 
TABLE 1. Summary of pediatric intracranial aneurysms treated with flow diversion

\begin{tabular}{|c|c|c|c|c|c|}
\hline Authors \& Year & Age, Sex & Morphology/Location/Type of Aneurysm & $\begin{array}{l}\text { Size } \\
(\mathrm{mm})\end{array}$ & Treatment & FU \\
\hline Current study & $9 \mathrm{mos}, \mathrm{F}$ & Saccular, posttraumatic It $M_{1}$ pseudoaneurysm & 16 & Coil, PED w/ coil & 7 mos, total occlusion \\
\hline Sastry et al., 2018 & 13 yrs, $M$ & Saccular, posttraumatic basilar tip & 5.4 & Coil, PED & 7 mos, total occlusion \\
\hline Vachhani et al., 2016 & $12 \mathrm{yrs}, \mathrm{F}$ & Fusiform It $A_{2}$ & 6.2 & PED $\times 2$ & $1 \mathrm{yr}$, total occlusion \\
\hline Kan et al., 2015 & 16 yrs, $M$ & Fusiform basilar trunk & Giant & Surpass & 6 mos, total occlusion \\
\hline \multirow[t]{2}{*}{ Lin et al., 2016} & 13 yrs, $M$ & Dissecting $A_{2}$ & NA & PED & Total occlusion at last angio \\
\hline & 16 yrs, M & Fusiform $\mathrm{M}_{2}$ & NA & Clip, bypass, PED $\times 3$ & Total occlusion at last angio \\
\hline \multirow[t]{2}{*}{ Vargas et al., 2016} & 8 yrs, M & Saccular, posttraumatic $A_{2}$ & 4 & PED & 8 mos, total occlusion \\
\hline & 9 yrs, M & $\begin{array}{l}\text { Fusiform, vasculopathic basilar, \& petrocav- } \\
\text { ernous }\end{array}$ & 20,30 & PED $\times 2$ & 24 mos, partial occlusion \\
\hline \multirow[t]{2}{*}{ Navarro et al., 2015} & $11 \mathrm{yrs}, \mathrm{F}$ & Saccular, vasculopathic vertebrobasilar, \& ICA & Large & PED $\times 2$ & 12 mos, total occlusion \\
\hline & 4 yrs, M & Saccular PCoA & Small & Coil, PED & 6 mos, total occlusion \\
\hline Ikeda et al., 2015 & $12 \mathrm{yrs}, \mathrm{F}$ & Fusiform $\mathrm{M}_{2}$ & 26 & Clip, PED & 6 mos, total occlusion \\
\hline Abla et al., 2014 & $10 \mathrm{yrs}, \mathrm{M}$ & Fusiform, vasculopathic ICA & Giant & PED $\times 7$, bypass & $\begin{array}{l}9 \text { mos, recurrence, STA-MCA } \\
\text { open bypass offered }\end{array}$ \\
\hline Zarzecka et al., 2014 & $15 \mathrm{yrs}, \mathrm{M}$ & Fusiform $\mathrm{V}_{4}$ & Giant & PED $\times 2$ & $2 \mathrm{yrs}$, total occlusion \\
\hline Çinar et al., 2013 & $8 \mathrm{yrs}, \mathrm{F}$ & Saccular pre-petrous ICA & Giant & PED & 23 mos, total occlusion \\
\hline Burrows et al., 2013 & $15 \mathrm{yrs}, \mathrm{M}$ & Fusiform $\mathrm{M}_{2}$ & Large & Bypass, PED $\times 3$ & 10 mos, total occlusion \\
\hline \multirow[t]{3}{*}{ de Barros et al., 2011} & 12 yrs, F & Dissecting basilar trunk & Giant & PED $\times 2$ & Incomplete occlusion, lost to FU \\
\hline & 5 yrs, F & Dissecting basilar tip & Small & PED $\times 2$ & 3 mos, total occlusion \\
\hline & $7 \mathrm{yrs}, \mathrm{M}$ & Dissecting vertebrobasilar & Giant & PED $\times 4$ & 6 mos, total occlusion \\
\hline \multirow[t]{2}{*}{ Lubicz et al., 2010} & $17 \mathrm{yrs}, \mathrm{F}$ & Fusiform basilar & 14 & SILK & NA \\
\hline & $10 \mathrm{yrs}, \mathrm{F}$ & Saccular cavernous ICA & 22 & SILK & NA \\
\hline Appelboom et al., 2010 & $10 \mathrm{yrs}, \mathrm{F}$ & Infectious cavernous ICA & Giant & SILK & 3 mos, total occlusion \\
\hline Crowley et al., 2009 & 22 mos, M & Fusiform basilar & 16 & Enterprise $\times 3$ & 4 mos, trace filling \\
\hline
\end{tabular}

Angio = angiogram; $\mathrm{FU}=$ follow up; $\mathrm{NA}=$ not applicable; $\mathrm{PCOA}=$ posterior communicating artery.

left temporal mass on MRI. She underwent left temporal craniotomy for resection at an outside institution, where the mass was found to be adherent to the left MCA. Grosstotal resection was achieved, but removal of the tumor from the MCA resulted in injury to the vessel. Final pathology revealed Grade 1 desmoplastic infantile ganglioglioma, a benign tumor. Postoperatively, the patient had a dense right hemiparesis. She was discharged to neurorehabilitation with improving motor function; however, within a week she developed irritability, worsening weakness, and lethargy. Cranial CT without contrast showed intraparenchymal hemorrhage within the operative bed and left sylvian fissure subarachnoid hemorrhage (Fig. 1A). Cerebral angiography at an outside institution demonstrated an irregular, $8 \times 9-\mathrm{mm}$ anterior projecting distal left $\mathbf{M}_{1}$ segment pseudoaneurysm just proximal to the MCA bifurcation, which was the cause of the patient's hemorrhage (Fig. 1B). Treatment was deferred and she was transferred to our care. Within a day of arrival, the patient developed seizures, lethargy, and hypertension. An ultrafast MR image showed a new $2.6-\mathrm{cm}$ left hemispheric acute subdural hematoma and enlarging left basal ganglia hemorrhage with $1.7-\mathrm{cm}$ midline shift and associated subfalcine and uncal herniation consistent with pseudoaneurysm re-rupture (Fig. 1C).

\section{Examination}

The patient was difficult to arouse at initial examination upon presentation to our institution. Her occipitofrontal circumference was $45 \mathrm{~cm}$. Pupils were small but reactive with right-sided facial asymmetry. She had positive corneal and cough reflexes. Antigravity movements in the left upper and lower extremities were observed but the patient had no spontaneous movement on the right side. Her anterior fontanelle was bulging and tense.

\section{Initial Operative/Endovascular Management}

The patient was emergently taken to the operating room for decompressive craniectomy and evacuation of the subdural hematoma. The decision was made to avoid violation of the intraparenchymal hematoma due to concern for uncontrollable hemorrhage from the pseudoaneurysm. The patient was taken directly to the interventional neuroradiology suite after the craniectomy. Endovascular coil embolization was pursued due to the high-risk nature of open microsurgical clipping, which likely would require MCA vessel sacrifice in the setting of no viable left superficial temporal artery (STA) for bypass secondary to her previous surgeries. A 4-Fr 30-cm Flexor sheath was introduced in the left femoral artery. This was advanced over a 4-Fr JB-1 diagnostic catheter into the distal left common 

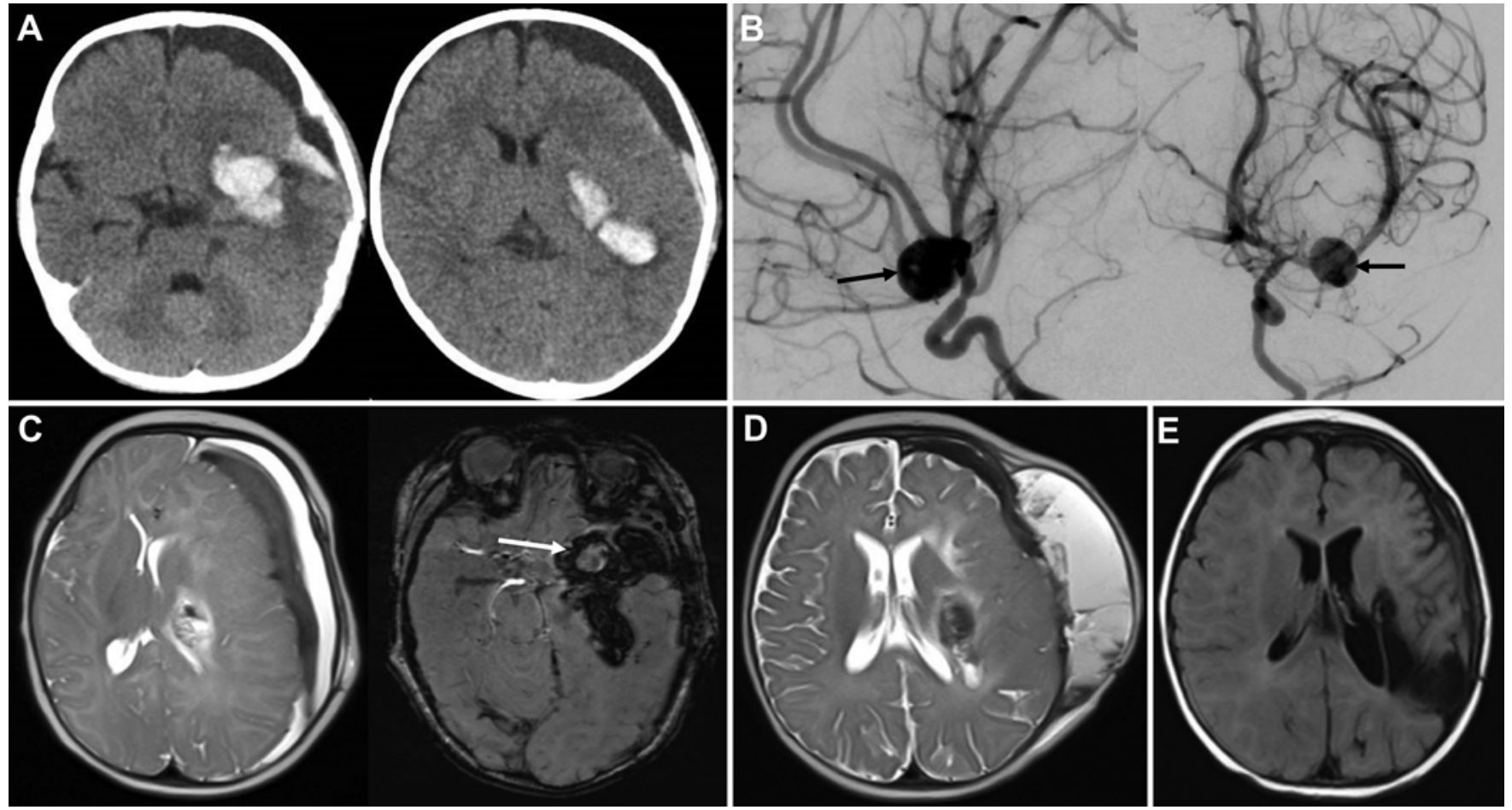

FIG. 1. Radiology and operative/postoperative course. A: Initial cranial CT showing acute multicompartment intracranial hemorrhage centered in the left sylvian fissure and basal ganglia with left frontal subdural collection. B: Cerebral angiography demonstrates an irregular $8 \times 9-\mathrm{mm}$ anteriorly projecting pseudoaneurysm of the distal left $\mathrm{M}_{1}$ segment (arrow) just proximal to the MCA bifurcation. C: Ultrafast MRI (T2-weighted and susceptibility weighted imaging sequences) showing worsening left hemispheric subdural hematoma and enlarging left basal ganglia hemorrhage surrounding the left $\mathrm{M}_{1}$ pseudoaneurysm (arrow) with associated midline shift. D: Subgaleal fluid collection $(9.3 \times 2.8 \times 8.7 \mathrm{~cm})$ noted on MRI after the patient suffered a CSF leak and examination deterioration. E: Three-month postcranioplasty MRI (T2-weighted FLAIR sequences) showing expected encephalomalacia and resolution of subdural hematoma and midline shift.

carotid artery. A 0.038-inch ID 125-cm distal access catheter (Stryker Neurovascular) and a Headway Duo 156-cm microcatheter (MicroVention) were coaxially introduced over a Synchro 2 microwire into the distal left internal carotid artery (ICA) and then into the left MCA. Selective angiography showed interval decrease in the size of the aneurysm to $4.9 \times 3.6 \mathrm{~mm}$ in transverse dimension with pre-aneurysmal $\mathrm{M}_{1}$ stenosis of $0.9 \mathrm{~mm}$ secondary to spasm or dissection (Fig. 2A). The aneurysm was accessed by the Headway Duo microcatheter and coil embolization proceeded. The aneurysm dome was occluded without contrast extravasation or coil prolapse within the parent vessel (Raymond-Roy Class II; Fig. 2B).

\section{Postoperative Course and Follow-Up}

After the procedure, the patient was observed in the pediatric intensive care unit with improvement on her neurological examination. However, over the next few days, she developed significant swelling in the decompressive bone defect and CSF leakage, and experienced another seizure. Repeat ultrafast MRI showed increased herniation of brain tissue through the craniectomy defect with persistent subdural hematoma and fluid collection in the subgaleal space (Fig. 1D). The patient was brought back to the operating room for right external ventricular drain (EVD) placement, surgical wound reexploration, evacua- tion of subdural hematoma, and autologous cranioplasty. Her EVD was eventually weaned without CSF leakage or wound dehiscence (Fig. 1E).

At 1-month follow-up, CT angiography demonstrated residual filling of the pseudoaneurysm with coil compaction (Fig. 2C). The stenosis of the left $\mathrm{M}_{1}$ proximal and distal to the aneurysm remained stable. Treatment was deferred at the time to allow for the infant to return to her ideal weight nomogram and to continue neurorehabilitation. These radiographic findings were confirmed on surveillance MR angiography (MRA) at 2 months followup, where the aneurysm had recanalized and measured $1.9 \times 1.2 \mathrm{~cm}$ with morphological irregularity (Fig. 2D). Clinically, the patient was neurologically improved with near full strength in the right upper and lower extremities. However, given the rapid recurrence of the aneurysm and high risk for rehemorrhage, it was decided that repeat endovascular treatment using a definitive flow diversion strategy would be favored over continued observation.

\section{PED Embolization and Antiplatelet Regimen}

The patient was preadmitted 7 days prior to PED treatment and started on $5 \mathrm{mg} / \mathrm{kg}$ of aspirin and $1 \mathrm{mg} / \mathrm{kg}$ of clopidogrel daily (based on a weight of $11 \mathrm{~kg}$ ) in preparation for the flow diverter placement. A P2Y12 assay was measured at 35 platelet response units (PRU) on the day 

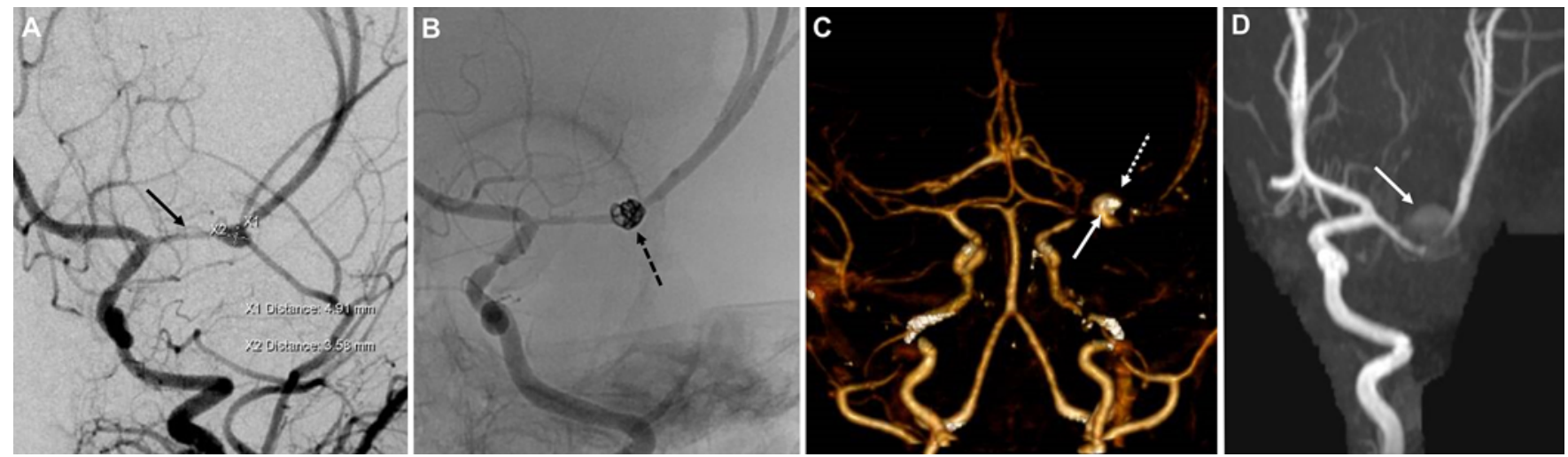

FIG. 2. Coil embolization. A: Selective angiography demonstrates interval decrease in the size of the aneurysm to $4.9 \times 3.6 \mathrm{~mm}$ after the re-rupture event, with the small-caliber $\mathrm{M}_{1}$ (arrow) to $0.9 \mathrm{~mm}$, likely secondary to vasospasm. B: Dome occlusion was noted after coil embolization (arrow). C: One-month follow-up CT angiogram shows recanalization of the aneurysm up to $1.6 \times 1.2$ $\mathrm{cm}$ (solid arrow), with coil pack compaction lateral to the aneurysm base (dashed arrow). D: Two-month follow-up MRA demonstrates further expansion of the aneurysm sac to $1.9 \times 1.2 \mathrm{~cm}$. Figure is available in color online only.

after dual antiplatelet loading. As such, clopidogrel was decreased to $2.4 \mathrm{mg}$ daily and the patient's PRU normalized to a therapeutic range between 109 and 224. The patient was placed under general anesthesia and a 5-Fr Flexor $30-\mathrm{cm}$ sheath was introduced into the right femoral artery using a micropuncture technique. The femoral arteries were evaluated at the time of the procedure as we utilized ultrasound-guided femoral access. This procedure demonstrated adequate size for a 5-Fr sheath. Furthermore, the right leg was monitored for ischemia with pulse oximetry of the toes. Systemic heparinization was instituted. The 5-Fr Flexor sheath was advanced over a 5-Fr JB-1 catheter into the left common carotid artery. A 0.058-inch Navien catheter was coaxially introduced and advanced over a 0.027-inch VIA microcatheter (Sequent Medical/ MicroVention) tracking over a Fathom 16 microwire into the petrous ICA. Control angiography again demonstrated the 19-mm aneurysm with coil compaction (Fig. 3A). The VIA microcatheter was removed and an SL-10 coiling microcatheter (Stryker Neurovascular) was introduced and placed within the aneurysm sac. Partial coil embolization was performed with 5 coils placed in the aneurysm dome (Fig. 3B). The SL-10 microcatheter was then withdrawn and the VIA microcatheter was tracked over the Fathom microwire into the distal left MCA and the PED was introduced into the catheter (Fig. 3C). At this point, a $2.5 \times$ 16-mm PED was deployed under continuous fluoroscopy (Fig. 3D). After PED deployment angiography was performed immediately and then at 10, 60, and 120 minutes (Fig. 3E) to ensure there was no in situ thrombosis. After the procedure, primary surgical femoral arteriotomy closure was performed by vascular surgery in the operating room; this eliminated the potential for a groin hematoma complication that would require the reversal of anticoagulation and antiplatelet medications.

Following the procedure, the patient was maintained in the hospital for several days and received $5 \mathrm{mg} / \mathrm{kg}$ of aspirin and $2.4 \mathrm{mg}$ of clopidogrel daily. She was discharged home under the care of her parents. The patient did have bruising and small petechiae at the 1-month follow-up clinic visit and her clopidogrel regimen was changed to every other day. At the 3-month clinical follow-up, the clopidogrel regimen was further down-titrated to every 3 days. Surveillance MRA at 7 months after the procedure showed no evidence of residual aneurysm filling (Fig. 3F) with stable left proximal $\mathrm{M}_{1}$ vessel caliber. Clinically, her hemiparesis resolved completely and she remained neurologically intact on examination. The patient's dual antiplatelet regimen was further down-titrated to $2.4 \mathrm{mg}$ of clopidogrel once a week and $40.5 \mathrm{mg}$ of aspirin daily.

\section{Discussion}

Pediatric brain aneurysms are rare clinical entities with unique management considerations. ${ }^{24}$ Different from adult aneurysms, pediatric aneurysms tend to be larger, frequently nonsaccular, and more likely located in the posterior circulation. ${ }^{35}$ Both microsurgical and endovascular management have additional technical challenges, as the brain vasculature and operative field are smaller and the vessels commonly more friable, and there is much less leniency with operative blood loss and hemodynamic instability.

In our case, the patient was otherwise developmentally normal but the pseudoaneurysm formed after traumatic manipulation of the left MCA during resection of a benign brain tumor. She also suffered two acute aneurysmal rupture events, the second of which required emergency decompressive craniectomy. Open microsurgical clip placement was deferred at the time of craniectomy due to concern for uncontrollable hemorrhage risking exsanguination in this then 5-month-old infant, as well as the high risk for needing to sacrifice the parent MCA during treatment. As such, endovascular embolization was offered, initially with coil embolization.

Prior to the advent of flow diverters, endovascular treatment of pediatric intracranial aneurysms consisted mainly of coil embolization or stent-assisted coil embolization, and parent vessel occlusion. ${ }^{40,44}$ Although periprocedural morbidity is lower in children treated with endovascular therapy compared to open surgery, ${ }^{2}$ long-term treatment durability was initially subject to debate, with aneurysm 

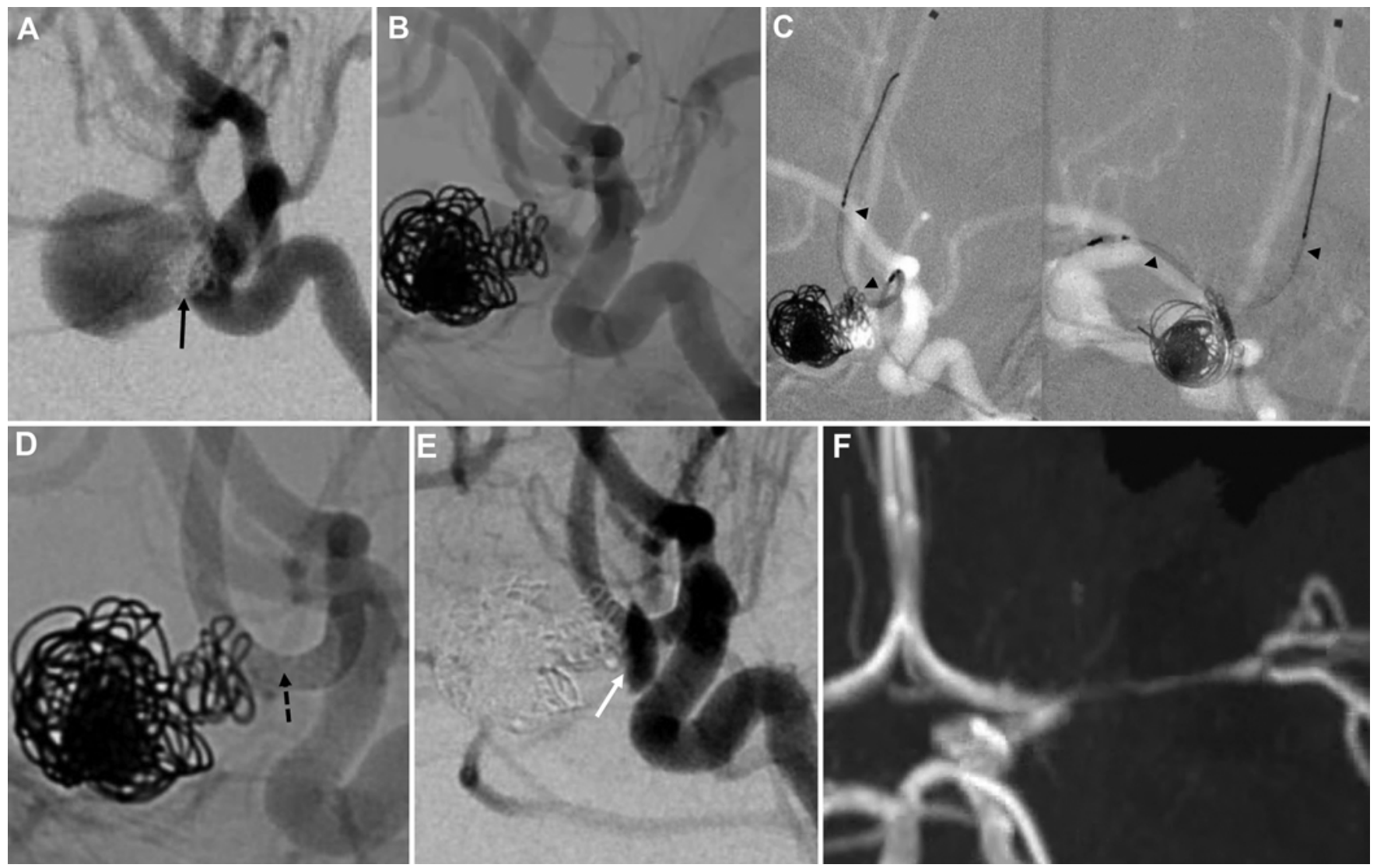

FIG. 3. PED-assisted coil embolization. A: Pre-PED selective angiography shows the recurrent aneurysm with coil compaction at the base of the aneurysm (arrow). B: Lateral native fluoroscopy after coil embolization shows 5 coils within the dome of the aneurysm and preserved filling of the neck. C: The predeployed PED is visualized through the 0.027 -inch VIA microcatheter across the neck of the aneurysm (arrowheads) on the anteroposterior and lateral angiograms. D: Single-shot native fluoroscopy demonstrating successful deployment of the PED without in-stent thrombosis or wall malapposition (arrow). E: Post-PED angiography shows obliteration of the aneurysm dome and profound flow diversion-induced contrast stasis in the residual fusiform base segment of the aneurysm (arrow). F: Seven-month post-PED follow-up MRA shows no evidence of residual filling or aneurysm recurrence, with stable $\mathrm{M}_{1}$ caliber.

recurrence rates as high as $14 \%$ in one series. ${ }^{39}$ However, recent studies have shown endovascular obliteration rates as high as $96 \%$ at 3-year follow-up, ${ }^{40}$ which is comparable to the $94 \%$ obliteration rate reported for open microsurgical management. ${ }^{27}$ In our patient, the aneurysm recanalized within 1 month after initial successful coil embolization. The rapid recurrence demonstrates the importance of close radiographic surveillance, particularly in infants with posttraumatic pseudoaneurysms.

The use of flow diverters in the pediatric population has been limited, with only 21 patients ( 22 aneurysms) re-

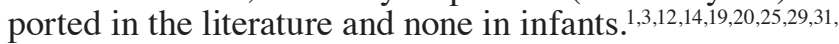
32,35,41,46,48,49 These studies are summarized in Table 1 and include aneurysms treated with PED, SILK (Balt Extrusion), and Surpass (Stryker Neurovascular) flow diverters. One case from Crowley et al. in 2009 utilized three telescoping Cordis Enterprise microstents to treat a fusiform basilar aneurysm in a 22-month-old child, who was previously the youngest patient treated with a flow diversion strategy. ${ }^{19}$ Overall, 17 of 23 aneurysms had near-total or total occlusion at the last follow-up evaluation, 4 with partial occlusion, and 2 (both SILK) did not have follow-up data. Although Abla et al. reported a case of a giant supraclinoid ICA aneurysm recurrence despite 7 telescoping PEDs that required open surgical bailout with STA-MCA bypass, ${ }^{1}$ there are at least 3 cases of PEDs used as rescue/ salvage therapy after failed open surgical treatment. . $^{12,25,31}$ These PED-salvaged aneurysms are likely reflective of the previous tendency to use microsurgery as the front-line treatment for pediatric aneurysms.

In the present case, our patient was only 9 months old when she underwent PED-assisted coil embolization (Fig. 4). The patient's small size and weight (11 kg) presented unique technical challenges, in particular with titration of antiplatelet therapy. Dual antiplatelet therapy is necessary to prevent thromboembolic events related to PEDs; however, it is relatively contraindicated in the setting of acute aneurysmal rupture and recent surgery. Studies in the pediatric population have suggested starting with 81 $\mathrm{mg}$ of aspirin and $0.2-1 \mathrm{mg} / \mathrm{kg} / \mathrm{day}$ of clopidogrel 1 week before the procedure and titrating according to the P2Y12 results. ${ }^{15,35}$ The P2Y12 assay (VerifyNow, Accumetrics) is routinely used as a marker of responsivity to platelet aggregation inhibition with clopidogrel. The data are ex- 


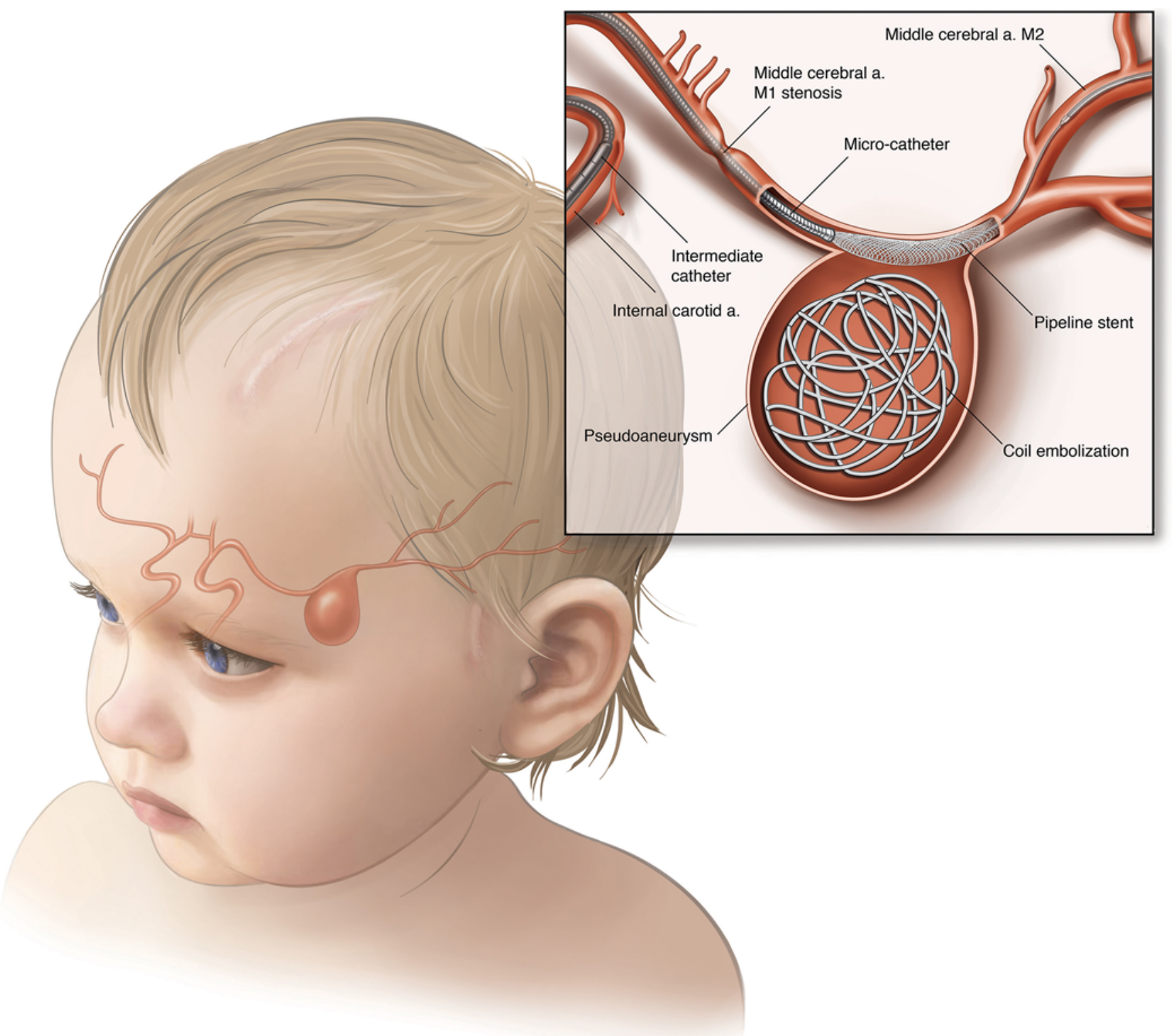

FIG. 4. Artistic rendering of the patient's endovascular treatment with PED-assisted coil embolization. a. = artery. Copyright Tess Marhofer. Published with permission. Figure is available in color online only.

trapolated from the adult population and the actual benefit of achieving an optimal target PRU is controversial.9,21,23,45 Furthermore, the dual antiplatelet dosing regimen and optimal PRU range for flow diversion in the infant population is not established.

We admitted our patient to a monitored setting 7 days prior to the PED and initiated $5 \mathrm{mg} / \mathrm{kg} /$ day of aspirin and $1 \mathrm{mg} / \mathrm{kg} /$ day of clopidogrel. The initial clopidogrel dosing $(1 \mathrm{mg} / \mathrm{kg} /$ day $)$ was in accordance with protocols from published reports by Finkelstein et al. ${ }^{22}$ and Soman et al. ${ }^{43}$ P2Y12 levels were drawn daily, which necessitated the placement of a peripherally inserted central catheter line due to difficult vascular access. The PRU was 35 on the first day after dual antiplatelet loading. As such, clopidogrel was decreased to $2.4 \mathrm{mg}$ daily (approximately 0.2 $\mathrm{mg} / \mathrm{kg} /$ day) and P2Y12 normalized to an optimal range between 109 and 224 over the course of the week. This dose titration protocol was previously described by Cobb et al. ${ }^{15}$ and Li et al. ${ }^{30}$ as part of the PICOLO (Platelet Inhibition in Children on Clopidogrel) trial, which concludes that clopidogrel as low as $0.2 \mathrm{mg} / \mathrm{kg} /$ day in children $0-24$ months of age achieves a mean platelet inhibition level of $49 \%$, the equivalent of adults taking $75 \mathrm{mg} / \mathrm{day}$. We continued the patient on $5 \mathrm{mg} / \mathrm{kg} /$ day of aspirin and $0.2 \mathrm{mg} /$ $\mathrm{kg}$ /day of clopidogrel after the procedure and eventually decreased her clopidogrel frequency to once a week after the 7-month follow-up MRA confirmed aneurysmal occlusion and small, non-flow-limiting $\mathrm{M}_{1}$ vessel caliber.

To our knowledge, there are no longitudinal studies on the long-term use of antiplatelet therapy beginning in in- 
fancy. There is also no clear consensus about the optimal duration of antiplatelet usage in the pediatric intracranial stent and flow diversion population. Lifelong secondary prevention has never been investigated in the pediatric population, and this is a consideration that warrants further evaluation. ${ }^{42} \mathrm{~A}$ major risk of long-term antiplatelet therapy in infancy is the predisposition for this cohort, along with the pediatric population, to have frequent traumatic bumps and falls that are otherwise benign but can have catastrophic consequences when the patient is receiving systemic anticoagulation treatment. We advocate for close outpatient follow-up and titration of antiplatelet therapy based on radiographic and clinical results, with the goal of weaning patients off dual antiplatelet therapy and eventually to $81 \mathrm{mg}$ of aspirin daily as soon as possible.

In this infant, due to anatomical limitations in body size and vasculature diameter, we elected for a $35-\mathrm{cm} 5-\mathrm{Fr}$ femoral "long" sheath, which was advanced into position over a standard 5-Fr diagnostic JB-1 catheter. The catheter could only be placed in the distal left common carotid artery. Considering this, a 5-Fr 0.058-inch Navien catheter was introduced and tracked into the petrous carotid. Although we commonly track the distal intracranial catheter into the supraclinoid ICA for deployment of PEDs in the MCA, a more proximal position in this case was believed sufficient for deployment and less risk of dissection and flow-limiting vasospasm. This 5-Fr access platform prevented the ability to use a parallel microcatheter (jailing) technique and necessitated sequential coiling followed by flow diversion. The small size of the left $\mathrm{M}_{1}$ segment $(<1.0$ $\mathrm{mm}$ ) raised further concerns for the simultaneous placement of 0.027 -inch and 0.0165 -inch catheters through this vessel. If a jailing technique had been used, the position of the SL-10 microcatheter within the small-caliber parent vessel between the deployed PED and vessel wall could increase the risk for in situ thrombosis and intraprocedural aneurysm rupture. Furthermore, before PED deployment the malleable nature of the patient's parent vessels caused dramatic straightening of the cavernous ICA genus system with resultant rapid forward movement of the 0.027-inch catheter. This event was not encountered in our experience with more than 750 adult PED cases and further illustrates the inherent challenges of navigating pliable parent vasculature in an infant.

It is important to note that the patient's aneurysm had previously ruptured and continued to enlarge despite initial coiling, likely through a small pinhole opening, an anatomical setup for delayed rupture due to inflow and outflow mismatch. Considering this arrangement, a singlestage PED-assisted coil embolization strategy was chosen. While some studies have reported ischemic strokes attributed to occlusion of perforating arteries from PED coverage, ${ }^{34,47}$ we have not observed symptomatic perforator infarctions in our large adult experience, even despite cases of overlapping PEDs. ${ }^{17}$ During coiling, we elected to perform a loose packing with 5 large-diameter coils. The goal was to achieve dome protection while intending to leave a neck residual, due to concern that thrombosis of the aneurysm neck could extend into the small-caliber parent vessel and cause occlusion. At the end of the coiling procedure, control angiography demonstrated no flow delay out of the MCA with maintained patency and luminal caliber of the parent vessel, at which time PED deployment was deemed safe. Considering the propensity for in-stent thrombosis in small-vessel PED cases, the patient was kept under general anesthesia for an additional 2 hours after PED deployment, during which time control angiography was performed.

With regard to radiographic follow-up, endosaccular occlusion noted on the 7-month postprocedure MRI/MRA could be considered definitive treatment success. Noninvasive imaging modalities such as contrast-enhanced and time-of-flight MRA have been used routinely in the adult flow diversion follow-up literature. ${ }^{13,36,37}$ Extrapolating from the adult PED data, endosaccular aneurysm obliteration at 6 months postprocedure provides us with assurance of long-term occlusion and healing, particularly for aneurysms treated with adjunctive coiling. ${ }^{8}$

The use of flow diversion for pediatric intracranial aneurysms is still in its early stages. For complex recurrent aneurysms, even in the youngest of patients, flow diversion is an important modern tool of neurointervention that can be safely and effectively utilized as an alternative therapy to traditional approaches. Long-term large cohort studies in children could further delineate the role of flow diversion in this population.

\section{Acknowledgments}

We would like to thank Tess Marhofer for her masterful illustration, which artfully demonstrates the nuances of this case.

\section{References}

1. Abla AA, Zaidi HA, Crowley RW, Britz GW, McDougall CG, Albuquerque FC, et al: Optic chiasm compression from mass effect and thrombus formation following unsuccessful treatment of a giant supraclinoid ICA aneurysm with the Pipeline device: open surgical bailout with STA-MCA bypass and parent vessel occlusion. J Neurosurg Pediatr 14:31-37, 2014

2. Alawi A, Edgell RC, Elbabaa SK, Callison RC, Khalili YA, Allam H, et al: Treatment of cerebral aneurysms in children: analysis of the Kids' Inpatient Database. J Neurosurg Pediatr 14:23-30, 2014

3. Appelboom G, Kadri K, Hassan F, Leclerc X: Infectious aneurysm of the cavernous carotid artery in a child treated with a new-generation of flow-diverting stent graft: case report. Neurosurgery 66:E623-E624, 2010

4. Awad AJ, Mascitelli JR, Haroun RR, De Leacy RA, Fifi JT, Mocco J: Endovascular management of fusiform aneurysms in the posterior circulation: the era of flow diversion. Neurosurg Focus 42(6):E14, 2017

5. Becske T, Brinjikji W, Potts MB, Kallmes DF, Shapiro M, Moran CJ, et al: Long-term clinical and angiographic outcomes following Pipeline Embolization Device treatment of complex internal carotid artery aneurysms: five-year results of the Pipeline for Uncoilable or Failed Aneurysms trial. Neurosurgery 80:40-48, 2017

6. Becske T, Potts MB, Shapiro M, Kallmes DF, Brinjikji W, Saatci I, et al: Pipeline for uncoilable or failed aneurysms: 3-year follow-up results. J Neurosurg 127:81-88, 2017

7. Bender MT, Colby GP, Jiang B, Lin LM, Campos JK, Xu R, et al: Flow diversion of posterior circulation cerebral aneurysms: a single-institution series of 59 cases. Neurosurgery [epub ahead of print], 2018

8. Bender MT, Colby GP, Lin LM, Jiang B, Westbroek EM, Xu $\mathrm{R}$, et al: Predictors of cerebral aneurysm persistence and oc- 
clusion after flow diversion: a single-institution series of 445 cases with angiographic follow-up. J Neurosurg [epub ahead of print March 30, 2018. DOI: 10.3171/2017.11.JNS171738]

9. Bender MT, Lin LM, Colby GP, Lubelski D, Huang J, Tamargo RJ, et al: P2Y12 hyporesponse (PRU>200) is not associated with increased thromboembolic complications in anterior circulation Pipeline. J Neurointerv Surg 9:978-981, 2017

10. Bender MT, Wendt H, Monarch T, Lin LM, Jiang B, Huang $\mathrm{J}$, et al: Shifting treatment paradigms for ruptured aneurysms from open surgery to endovascular therapy over 25 years. World Neurosurg 106:919-924, 2017

11. Bhogal P, AlMatter M, Bäzner H, Ganslandt O, Henkes H, Aguilar Pérez M: Flow diversion for the treatment of MCA bifurcation aneurysms - a single centre experience. Front Neurol 8:20, 2017

12. Burrows AM, Zipfel G, Lanzino G: Treatment of a pediatric recurrent fusiform middle cerebral artery (MCA) aneurysm with a flow diverter. J Neurointerv Surg 5:e47, 2013

13. Chalouhi N, Zanaty M, Whiting A, Yang S, Tjoumakaris S, Hasan D, et al: Safety and efficacy of the Pipeline Embolization Device in 100 small intracranial aneurysms. J Neurosurg 122:1498-1502, 2015

14. Çinar C, Bozkaya H, Oran I: Endovascular treatment of cranial aneurysms with the pipeline flow-diverting stent: preliminary mid-term results. Diagn Interv Radiol 19:154-164, 2013

15. Cobb MIH, Zomorodi AR, Hauck EF, Smith TP, Fernando Gonzalez L: Optimal pediatric dosing of anti-platelet agents for pipeline stent embolization-a case report and review of the literature. Childs Nerv Syst 33:685-690, 2017

16. Colby GP, Bender MT, Lin LM, Beaty N, Caplan JM, Jiang $\mathrm{B}$, et al: Declining complication rates with flow diversion of anterior circulation aneurysms after introduction of the Pipeline Flex: analysis of a single-institution series of 568 cases. J Neurosurg [epub ahead of print January 12, 2018. DOI: 10.3171/2017.7.JNS171289]

17. Colby GP, Bender MT, Lin LM, Beaty N, Huang J, Tamargo RJ, et al: Endovascular flow diversion for treatment of anterior communicating artery region cerebral aneurysms: a single-center cohort of 50 cases. J Neurointerv Surg 9:679685, 2017

18. Colby GP, Lin LM, Caplan JM, Jiang B, Huang J, Tamargo RJ, et al: Immediate procedural outcomes in 44 consecutive Pipeline Flex cases: the first North American single-center series. J Neurointerv Surg 8:702-709, 2016

19. Crowley RW, Evans AJ, Kassell NF, Jensen ME, Dumont AS: Endovascular treatment of a fusiform basilar artery aneurysm using multiple "in-stent stents". Technical note. J Neurosurg Pediatr 3:496-500, 2009

20. de Barros Faria M, Castro RN, Lundquist J, Scrivano E, Ceratto R, Ferrario A, et al: The role of the pipeline embolization device for the treatment of dissecting intracranial aneurysms. AJNR Am J Neuroradiol 32:2192-2195, 2011

21. Delgado Almandoz JE, Crandall BM, Scholz JM, Fease JL, Anderson RE, Kadkhodayan Y, et al: Pre-procedure P2Y12 reaction units value predicts perioperative thromboembolic and hemorrhagic complications in patients with cerebral aneurysms treated with the Pipeline Embolization Device. J Neurointerv Surg 5 (Suppl 3):iii3-iii10, 2013

22. Finkelstein Y, Nurmohamed L, Avner M, Benson LN, Koren G: Clopidogrel use in children. J Pediatr 147:657-661, 2005

23. Goh C, Churilov L, Mitchell P, Dowling R, Yan B: Clopidogrel hyper-response and bleeding risk in neurointerventional procedures. AJNR Am J Neuroradiol 34:721-726, 2013

24. Huang J, McGirt MJ, Gailloud P, Tamargo RJ: Intracranial aneurysms in the pediatric population: case series and literature review. Surg Neurol 63:424-433, 2005

25. Ikeda DS, Marlin ES, Shaw A, Powers CJ: Successful endovascular reconstruction of a recurrent giant middle cerebral artery aneurysm with multiple telescoping flow diverters in a pediatric patient. Pediatr Neurosurg 50:88-93, 2015

26. Jiang B, Paff M, Colby GP, Coon AL, Lin LM: Cerebral aneurysm treatment: modern neurovascular techniques. Stroke Vasc Neurol 1:93-100, 2016

27. Kakarla UK, Beres EJ, Ponce FA, Chang SW, Deshmukh VR, Bambakidis NC, et al: Microsurgical treatment of pediatric intracranial aneurysms: long-term angiographic and clinical outcomes. Neurosurgery 67:237-250, 2010

28. Kallmes DF, Brinjikji W, Cekirge S, Fiorella D, Hanel RA, Jabbour P, et al: Safety and efficacy of the Pipeline embolization device for treatment of intracranial aneurysms: a pooled analysis of 3 large studies. J Neurosurg 127:775-780, 2017

29. Kan P, Mokin M, Puri AS, Wakhloo AK: Successful treatment of a giant pediatric fusiform basilar trunk aneurysm with surpass flow diverter. BMJ Case Rep 2015:bcr2015011718, 2015

30. Li JS, Yow E, Berezny KY, Bokesch PM, Takahashi M, Graham TP Jr, et al: Dosing of clopidogrel for platelet inhibition in infants and young children: primary results of the Platelet Inhibition in Children On cLOpidogrel (PICOLO) trial. Circulation 117:553-559, 2008

31. Lin N, Lanzino G, Lopes DK, Arthur AS, Ogilvy CS, Ecker $\mathrm{RD}$, et al: Treatment of distal anterior circulation aneurysms with the Pipeline embolization device: a US multicenter experience. Neurosurgery 79:14-22, 2016

32. Lubicz B, Collignon L, Raphaeli G, Pruvo JP, Bruneau M, De Witte O, et al: Flow-diverter stent for the endovascular treatment of intracranial aneurysms: a prospective study in 29 patients with 34 aneurysms. Stroke 41:2247-2253, 2010

33. Lyon KA, Arrey EN, Haider AS, Jeevan DS, Benardete EA: Endovascular treatment of a large ruptured middle cerebral artery bifurcation aneurysm in a 5-week-old infant: case report. J Neurosurg Pediatr 20:357-363, 2017

34. Martínez-Galdámez M, Pérez S, Vega A, Ruiz P, Caniego JL, Bárcena E, et al: Endovascular treatment of intracranial aneurysms using the Pipeline Flex embolization device: a case series of 30 consecutive patients. J Neurointerv Surg 8:396-401, 2016

35. Navarro R, Brown BL, Beier A, Ranalli N, Aldana P, Hanel RA: Flow diversion for complex intracranial aneurysms in young children. J Neurosurg Pediatr 15:276-281, 2015

36. Nossek E, Chalif DJ, Chakraborty S, Lombardo K, Black KS, Setton A: Concurrent use of the Pipeline Embolization Device and coils for intracranial aneurysms: technique, safety, and efficacy. J Neurosurg 122:904-911, 2015

37. Park MS, Mazur MD, Moon K, Nanaszko MJ, Kestle JRW, Shah LM, et al: An outcomes-based grading scale for the evaluation of cerebral aneurysms treated with flow diversion. J Neurointerv Surg 9:1060-1063, 2017

38. Rajah G, Narayanan S, Rangel-Castilla L: Update on flow diverters for the endovascular management of cerebral aneurysms. Neurosurg Focus 42(6):E2, 2017

39. Sanai N, Quinones-Hinojosa A, Gupta NM, Perry V, Sun PP, Wilson CB, et al: Pediatric intracranial aneurysms: durability of treatment following microsurgical and endovascular management. J Neurosurg 104 (2 Suppl):82-89, 2006

40. Saraf R, Shrivastava M, Siddhartha W, Limaye U: Intracranial pediatric aneurysms: endovascular treatment and its outcome. J Neurosurg Pediatr 10:230-240, 2012

41. Sastry RA, Koch MJ, Grannan BL, Stapleton CJ, Butler WE, Patel AB: Flow diversion of a recurrent, iatrogenic basilar tip aneurysm in a pediatric patient: case report. J Neurosurg Pediatr 21:90-93, 2018

42. Simma B, Höliner I, Luetschg J: Therapy in pediatric stroke. Eur J Pediatr 172:867-875, 2013

43. Soman T, Rafay MF, Hune S, Allen A, MacGregor D, deVeber G: The risks and safety of clopidogrel in pediatric arterial ischemic stroke. Stroke 37:1120-1122, 2006 
44. Takemoto K, Tateshima S, Golshan A, Gonzalez N, Jahan R, Duckwiler G, et al: Endovascular treatment of pediatric intracranial aneurysms: a retrospective study of 35 aneurysms. J Neurointerv Surg 6:432-438, 2014

45. Taylor LI, Dickerson JC, Dambrino RJ, Kalani MYS, Taussky P, Washington CW, et al: Platelet testing in flow diversion: a review of the evidence. Neurosurg Focus 42(6):E5, 2017

46. Vachhani JA, Nickele CM, Elijovich L, Klimo P, Arthur AS: Flow diversion for treatment of growing A2 aneurysm in a child: case report and review of flow diversion for intracranial aneurysms in pediatric patients. World Neurosurg 96:607.e13-607.e17, 2016

47. van Rooij WJ, Sluzewski M: Perforator infarction after placement of a pipeline flow-diverting stent for an unruptured A1 aneurysm. AJNR Am J Neuroradiol 31:E43-E44, 2010

48. Vargas SA, Diaz C, Herrera DA, Dublin AB: Intracranial aneurysms in children: the role of stenting and flow-diversion. $\mathbf{J}$ Neuroimaging 26:41-45, 2016

49. Zarzecka A, Gory B, Turjman F: Implantation of two flow diverter devices in a child with a giant, fusiform vertebral artery aneurysm: case report. Pediatr Neurol 50:185-187, 2014

\section{Disclosures}

Dr. Coon is a proctor for the Woven Endobridge (WEB) device
(Sequent Medical); a proctor for the Surpass device (Stryker Neurovascular) and a consultant for Stryker Neurovascular; a proctor for the PED (Medtronic Neurovascular) and a consultant for Medtronic; and a proctor for the FRED device (MicroVention) and consultant for MicroVention. Dr. Colby is a proctor for the PED and consultant for Stryker Neurovascular. Dr. Lin is a proctor for the PED (Medtronic Neurovascular), is a consultant for MicroVention, and participates in a clinical trial for Stryker. Dr. Huang reports ownership in Longeviti.

\section{Author Contributions}

Conception and design: Coon, Jiang. Acquisition of data: Jiang, Bender, Xu. Analysis and interpretation of data: Colby, Xu. Drafting the article: Jiang, Bender, Westbroek, Xu, Campos. Critically revising the article: Coon, Colby, Jiang, Beaty, Westbroek, Xu,

Lin, Tamargo, Huang. Reviewed submitted version of manuscript: Coon, Bender, Westbroek, Tamargo, Huang. Approved the final version of the manuscript on behalf of all authors: Coon. Statistical analysis: Beaty. Administrative/technical/material support: Cohen. Study supervision: Coon, Cohen.

\section{Correspondence}

Alexander L. Coon: Johns Hopkins University School of Medicine, The Johns Hopkins Hospital, Baltimore, MD. acoon2@jhmi.edu. 